Arq. Bras. Med. Vet. Zootec., v.67, n.5, p.1390-1398, 2015

\title{
Utilização da biomassa remanescente de pastagens de estação fria para produção de forragem conservada
}

\author{
[Use of remaining biomass of cold season pastures for conserved forage production] \\ G.R. Meinerz ${ }^{1}$, C.J. Olivo ${ }^{2}$, J.L. Nörnberg², J. Viégas ${ }^{2}$, C.A. Agnolin², \\ R.B. Scheibler ${ }^{2}$, F.R. Skoniesk ${ }^{3}$, M.F. Ziech ${ }^{3}$, M.P. Quatrin ${ }^{2}$ \\ ${ }^{1}$ Universidade Federal da Fronteira Sul - UFFS - Campus de Cerro Largo, RS \\ ${ }^{2}$ Universidade Federal de Santa Maria - UFSM - Santa Maria, RS \\ ${ }^{3}$ Universidade Tecnológica Federal do Paraná - Dois Vizinhos, PR
}

\begin{abstract}
RESUMO
Esta pesquisa foi conduzida com o objetivo de avaliar a utilização da biomassa remanescente de pastagens de estação fria para produção de silagem e feno. As espécies testadas foram: aveia preta cv. Agro Zebu, azevém anual cv. Comum e trigo cv. BRS Tarumã. As forrageiras foram pastejadas por vacas em lactação da raça Holandesa, sob método de pastejo de lotação rotacionada. A silagem e o feno foram elaborados da biomassa remanescente das pastagens, 20 dias após o final do período de pastejo. $\mathrm{O}$ delineamento experimental foi o inteiramente ao acaso, em arranjo fatorial $3 \times 2$, com três repetições. Foram avaliados o rendimento de forragem, a composição botânica e a estrutural da forragem conservada, os parâmetros fermentativos da silagem e o valor nutritivo da silagem e do feno. O rendimento de forragem foi similar entre as espécies, e o material ensilado apresentou pequenos percentuais de lâminas foliares e grãos. A silagem apresentou características fermentativas desejáveis. A ensilagem apresentou menores perdas de componentes solúveis e proporcionou uma forragem com valor nutritivo mais elevado em relação à fenação, sendo a forma mais indicada para conservar a biomassa remanescente de pastagens de estação fria.
\end{abstract}

Palavras-chave: aveia, azevém, feno, silagem, trigo, valor nutritivo

\begin{abstract}
The aim of this research was to evaluate the use of cool season pastures' remaining biomass as conserved forage. The tested species were: Agro Zebu black oat, Common ryegrass and BRS Tarumã wheat. The pastures were grazed by Holstein dairy cows, in the rotating stocking grazing method. Hay and silage were done from the stubble of pasture, twenty days after the end of the grazing period. The experimental design was completely randomized, in a $3 \times 2$ factorial scheme, with tree replicates. Forage yield, structural and botanical composition of preserved forage, fermentative parameters and nutritive value of silage and hay were evaluated. Forage yield was similar among species, and ensiled material has small percentuals of leaf blades and grains. The silage presents desirables fermentation parameters. The silage had lower losses of soluble components, provides forage with a higher nutritional value compared to hay, and is the most appropriate way to conserve cool season remaining biomass.
\end{abstract}

Keywords: hay, nutritive value, oat, ryegrass, silage, wheat

\section{INTRODUÇÃO}

A utilização de forragens conservadas na alimentação de vacas leiteiras é uma prática bastante usual, sobretudo em períodos de carência de forragem, como o vazio forrageiro de outono. O principal objetivo dessa prática é suprir alimento volumoso de boa qualidade e em quantidades suficientes para a manutenção dos níveis de produtividade. Dentre as formas de

Recebido em 25 de fevereiro de 2014

Aceito em 27 de março de 2015

E-mail: gilmarmeinerz@yahoo.com.br 
conservação da forragem destacam-se a ensilagem e a fenação, que consistem no corte da planta forrageira em momento ideal e posterior armazenamento da massa verde. Quando realizado em condições ideais, o processo de conservação da forragem objetiva preservar a qualidade nutricional do material de origem (Van Soest, 1994).

As principais culturas usadas para produção de silagem são o milho e o sorgo, culturas típicas de verão. Em sistemas de integração lavourapecuária, essas culturas competem pelas áreas agricultáveis com cultivos que objetivam a produção comercial de grãos, sobretudo a soja e o próprio milho. Tal fato, aliado ao alto investimento requerido para desempenho satisfatório dessas culturas, faz com que o custo de produção de silagens de milho e sorgo seja elevado (Evangelista e Lima, 2000).

Nesse sentido, há necessidade de se estudar a viabilidade da utilização de outras culturas para produção de silagem, a fim de se reduzirem os custos de produção (Pinto et al., 2007). Com a expansão dos sistemas de produção baseados na integração lavoura-pecuária, a utilização mais racional de espécies forrageiras de estação fria constitui uma alternativa para produção de silagem de qualidade, com baixo custo, considerando-se que, no final do ciclo dessas culturas, normalmente há excedentes de forragem (Meinerz et al., 2011). Como resultado do manejo das pastagens, o sistema de integração lavoura-pecuária condiciona um resíduo no final do período de pastejo. Esse resíduo normalmente é utilizado como cobertura para a semeadura direta de culturas, mas pode ser usado como matéria-prima para a produção de forragens conservadas.

No Rio Grande do Sul, a utilização da biomassa remanescente de culturas de grãos, sobretudo do arroz, para alimentação de bovinos é uma prática bastante comum e de grande importância para o forrageamento dos animais no outono (Monks et al., 2002). Nessas situações, as sobras da lavoura e eventuais rebrotes podem ser conservados na forma de feno ou silagem. No entanto, a forragem desses materiais apresenta altos teores de lignina e sílica, com baixos coeficientes de digestibilidade (Monks et al., 2002). Considerando que a biomassa remanescente de forrageiras de estação fria é um material de melhor qualidade nutricional e que essas espécies são cultivadas em épocas com condições climáticas mais estáveis, a ensilagem ou a fenação desses materiais pode constituir estratégia importante de produção de forragens conservadas, com baixos custos.

Dentre essas forrageiras destacam-se o azevém anual (Lolium multiflorum Lam.) e novos genótipos de aveia (Avena sp.) e trigo (Triticum sativum L.) de duplo-propósito, de elevada produtividade. Há, no entanto, poucos estudos abordando o potencial de uso da biomassa remanescente dessas forrageiras. Assim, o objetivo do presente trabalho foi avaliar a produção de forragens conservadas, na forma de silagem e feno, mediante a utilização da biomassa remanescente de pastagens de estação fria.

\section{MATERIAL E MÉTODOS}

A pesquisa foi conduzida em área experimental do Laboratório de Bovinocultura de Leite e no Núcleo Integrado de Desenvolvimento de Análises Laboratoriais da Universidade Federal de Santa Maria. Localizada na região da Depressão Central do Rio Grande do Sul, apresenta altitude média de $95 \mathrm{~m}$. O solo da área experimental é classificado como argissolo vermelho distrófico arênico, pertencente à unidade de mapeamento São Pedro. Os dados da análise do solo foram os seguintes: índice SMP 5,$3 ; \quad \mathrm{P} \quad 3,7 \mathrm{mg} / \mathrm{dm}^{3} ; \mathrm{K} \quad 0,25 \mathrm{cmol}_{\mathrm{c}} / \mathrm{dm}^{3} ; \mathrm{Al}^{3+}$ $2,4 \mathrm{cmol}_{\mathrm{c}} / \mathrm{dm}^{3} ; \quad \mathrm{Ca}^{2+} \quad 2,8 \mathrm{cmol}_{\mathrm{c}} / \mathrm{dm}^{3} ; \quad \mathrm{Mg}^{2+}$ $1,6 \mathrm{cmol}_{\mathrm{c}} / \mathrm{dm}^{3}$; MO 3,9\%; saturação de bases $32,0 \%$ e saturação por alumínio $34 \%$.

O período experimental foi compreendido entre abril e novembro de 2009. As médias de temperatura diária e a precipitação pluviométrica mensal do período foram de $17,0^{\circ} \mathrm{C}$ e $130 \mathrm{~mm}$, similares às médias climáticas normais da região, mas com precipitação um pouco abaixo da normalidade. A área experimental foi de 1,0ha, dividida em nove piquetes de 0,1 ha cada, distribuídos ao acaso. Os tratamentos foram constituídos por três espécies forrageiras de estação fria: aveia preta (cv. Agro Zebu), azevém anual (cv. Comum) e trigo (cv. BRS Tarumã), pastejadas de forma rotacionada por vacas em lactação da raça Holandesa. 
A semeadura das forrageiras foi feita em 02 de abril, a lanço, com densidade de semeadura de 110,40 e $120 \mathrm{~kg} / \mathrm{ha}$ para aveia, azevém e trigo, respectivamente, mediante preparo convencional do solo. As adubações potássica e fosfórica foram feitas conforme as recomendações da Comissão de Química e Fertilidade do Solo RS/SC (2004). A adubação nitrogenada de cobertura, à base de ureia, foi de $150 \mathrm{~kg} / \mathrm{ha}$ de N para todas as espécies, dividida igualmente em quatro aplicações.

As forrageiras foram submetidas ao pastejo de lotação rotacionada com bovinos leiteiros, sendo realizados quatro pastejos para a aveia e cinco para o azevém e o trigo, com intervalos que variaram entre 21 e 32 dias. Os pastejos foram interrompidos quando as forrageiras atingiram o estádio reprodutivo. Vinte dias após o término dos pastejos, a biomassa remanescente das pastagens foi utilizada para conservação.

O rendimento de forragem foi estimado por meio de cinco amostras por piquete, cortadas rente ao solo, sendo utilizado um quadro com dimensões de $50 \times 50 \mathrm{~cm}$. As amostras foram homogeneizadas, sendo retirada uma subamostra para estimativa das composições botânica e estrutural da forragem, fazendo-se manualmente a separação da lâmina foliar, colmo+bainha, material senescente, espiga/panículas, grãos e outras espécies. Esses componentes foram secos em estufa de ar forçado a $55^{\circ} \mathrm{C}$ até peso constante para a determinação dos teores de matéria parcialmente seca.

A confecção das silagens e a do feno foram realizadas entre 10 de setembro e 02 de novembro. No dia da avaliação, a forragem foi cortada rente ao solo às oito horas, em cinco áreas por piquete determinadas aleatoriamente. Metade da forragem cortada foi triturada em moinho forrageiro regulado para fragmentar o material em partículas de $1,5 \mathrm{~cm}$. Esse material foi compactado manualmente em minissilos experimentais feitos de sacos plásticos duplos e sobrepostos, com peso aproximado de $10 \mathrm{~kg}$, e acondicionado em sala protegida da radiação solar. A outra metade foi colocada sobre uma lona plástica e exposta ao sol para desidratação até as 18 horas, quando a forragem foi acondicionada em fardos de, aproximadamente, $10 \mathrm{~kg}$, amarrados com cordas de sisal. Esses fardos foram acondicionados em local fresco e seco, protegidos da radiação solar e de roedores.

A abertura dos silos foi realizada após 90 dias de fermentação, desprezando-se a porção superior e as laterais de cada um. O restante do material foi homogeneizado, retirando-se uma subamostra para a determinação do $\mathrm{pH}$ em potenciômetro digital (Silva e Queiroz, 2002) e da capacidade tampão (Playne e McDonald, 1966). Com auxílio de uma prensa, foi retirado suco para a determinação do nitrogênio amoniacal (N-NH3) por destilação com óxido de magnésio (AOAC, 1995). O restante da amostra foi parcialmente seco em estufa de ventilação forçada, a $55^{\circ} \mathrm{C}$ até peso constante, sendo posteriormente moído em moinho do tipo Willey, com peneira com malha de $1 \mathrm{~mm}$, e acondicionado para a realização das análises laboratoriais. No mesmo dia da abertura dos silos, procedeu-se à abertura dos fardos de feno, adotando-se o mesmo procedimento de amostragem da silagem.

As determinações de matéria seca (MS), matéria orgânica (MO), fibra em detergente ácido (FDAc), lignina em detergente ácido (ácido sulfúrico), proteína bruta (PB), nitrogênio insolúvel em detergente neutro (NIDN) e nitrogênio insolúvel em detergente ácido (NIDA) foram realizadas segundo procedimentos descritos por Silva e Queiroz (2002). Para a determinação da fibra em detergente neutro corrigida para cinzas e proteína (FDNcp), não foi utilizado sulfito de sódio na solução em detergente neutro. Empregou-se $\alpha$-amilase termoestável, descontando-se a proteína insolúvel em detergente neutro e as cinzas residuais. Também foi determinada a fibra em detergente ácido corrigida para cinzas e proteína (FDAcp). As estimativas de carboidratos não fibrosos (CNF) e o teor de nutrientes digestíveis totais (NDT) foram calculados segundo Weiss et al. (1992).

O delineamento experimental utilizado foi $\mathrm{o}$ inteiramente ao acaso, em arranjo fatorial $3 \times 2$ (três espécies forrageiras $\mathrm{x}$ duas formas de conservação). Os resultados foram submetidos à análise de variância, e as médias comparadas entre si pelo teste de Tukey ao nível de 5\% de probabilidade do erro. 


\section{RESULTADOS E DISCUSSÃO}

As espécies testadas apresentaram ciclos de produção distintos, e a aveia foi a primeira a atingir a fase reprodutiva. A silagem e o feno de aveia foram feitos em 10 de setembro, 134 dias após a semeadura (Tab. 1), enquanto o azevém e o trigo apresentaram ciclos mais longos, com os cortes sendo feitos em 11 de outubro e 02 de novembro, respectivamente. A altura das plantas no momento do corte para conservação da forragem diferiu entre as espécies, tendo o trigo apresentado altura mais baixa em relação às demais, com valor próximo a $50 \mathrm{~cm}$.

No momento da abertura dos silos, não foi percebido odor de forragem apodrecida ou constatada presença de mofo, indicando que a fermentação ocorreu de forma adequada. Para a silagem, foram observados maiores teores de MS para o trigo e menores para a aveia. Ressalta-se que os teores de MS da aveia ficaram abaixo dos valores preconizados por Van Soest et al. (1994), entre 30 e $40 \%$, para que ocorram as menores perdas durante o processo fermentativo. Fisher e Burns (1987) afirmam que os clostrídios, considerados os principais microrganismos anaeróbicos que prejudicam a qualidade da silagem, são particularmente sensíveis à disponibilidade de água, sendo geralmente inativos em silagens com mais de $28 \%$ de MS. Em materiais com cerca de $15 \%$ de MS, valores de $\mathrm{pH}$ abaixo de 4 podem não inibir totalmente o seu crescimento (Edwards e McDonald, 1978). Os teores de MS obtidos neste trabalho são inferiores aos relatados por Fontaneli et al. (2009), que observaram teores entre 26 e $29 \%$ de MS para genótipos de aveia e $37-38 \%$ para genótipos de trigo.

Os teores de MS do feno também foram distintos entre as espécies, sendo maiores para o azevém e o trigo, com valores próximos a $80 \%$. O teor de MS do feno de aveia ficou próximo a $70 \%$, valor inferior ao considerado ideal para a conservação do feno, que é de $80 \%$ (Paz et al., 2000). Na abertura do feno de aveia, foi constatada presença significativa de fungos e forragem escurecida, indicando que esse material apresentava excesso de umidade quando foi enfardado. Provavelmente, o período de desidratação de 10 horas não foi suficiente para reduzir os teores de umidade da aveia devido às condições climáticas da época. Ressalta-se que, em condições de alta umidade, a intensa atividade de microrganismos promove aumento na temperatura do feno, podendo-se registrar valores acima de $65^{\circ} \mathrm{C}$ e até combustão espontânea. Temperaturas acima de $55^{\circ} \mathrm{C}$ são favoráveis à ocorrência de reações não enzimáticas entre os carboidratos solúveis e os grupos aminas dos aminoácidos, conhecidas como reações de Maillard (Van Soest, 1994).

Tabela 1. Rendimento de matéria seca e características da forragem pré-ensilada da biomassa remanescente de pastagens de forrageiras de estação fria

\begin{tabular}{|c|c|c|c|c|c|}
\hline \multirow{2}{*}{ Espécie } & \multirow{2}{*}{ Ciclo (dias) } & \multirow{2}{*}{ Altura $(\mathrm{cm})$} & \multicolumn{2}{|c|}{ MS (\%) } & \multirow{2}{*}{$\begin{array}{l}\text { Rendimento } \\
\text { (kg/ha de MS) }\end{array}$} \\
\hline & & & Silagem & Feno & \\
\hline Aveia & 134 & $86,9 a$ & $18,9 \mathrm{c}$ & $70,7 b$ & $3779 \mathrm{a}$ \\
\hline Azevém & 176 & $89,8 \mathrm{a}$ & $23,8 b$ & $79,9 a$ & $3562 \mathrm{a}$ \\
\hline Trigo & 165 & $49,8 b$ & $28,7 \mathrm{a}$ & $80,2 \mathrm{a}$ & $3510 \mathrm{a}$ \\
\hline CV $(\%)$ & - & 4,1 & 0,6 & 0,5 & 6,9 \\
\hline
\end{tabular}

Médias seguidas por letras distintas, na coluna, diferem entre si pelo teste Tukey a 5\% de probabilidade.

Com relação à produção de matéria seca (Tab. 1), não foram observadas diferenças entre as espécies. O rendimento médio obtido ficou em torno de $3600 \mathrm{~kg} / \mathrm{ha}$ de MS. Este resultado é inferior aos relatados por Fontaneli et al. (2009), ao avaliarem diferentes genótipos de cereais de inverno, submetidos ao corte. Floss et al. (2003) obtiveram 11,4t/ha de MS para silagem de aveia branca em um corte realizado no estádio de grão de massa dura.
A composição botânica e a estrutural da forragem conservada foram diferentes entre as espécies, sendo constituídas principalmente por colmos e material senescente, com pequenas contribuições de lâminas foliares e grãos. A participação de grãos, que confere maior qualidade às silagens, foi maior para o trigo, com valor próximo a $6 \%$, valor considerado baixo por tratar-se de um resíduo de forragem. 
Tabela 2. Composição botânica e estrutural (\% da massa seca total) da forragem pré-ensilada e préenfardada da biomassa remanescente de pastagens de estação fria

\begin{tabular}{lcccccc}
\hline Espécie & $\begin{array}{c}\text { Lâminas } \\
\text { foliares }\end{array}$ & $\begin{array}{c}\text { Colmo }+ \\
\text { bainha }\end{array}$ & $\begin{array}{c}\text { Material } \\
\text { morto }\end{array}$ & $\begin{array}{c}\text { Panícula/ } \\
\text { espiga }\end{array}$ & Grãos & $\begin{array}{c}\text { Outras } \\
\text { espécies }\end{array}$ \\
\hline Aveia & $7,0 \mathrm{~b}$ & $55,7 \mathrm{a}$ & $15,3 \mathrm{~b}$ & $7,2 \mathrm{~b}$ & $1,9 \mathrm{~b}$ & $12,9 \mathrm{a}$ \\
Azevém & $12,2 \mathrm{a}$ & $52,0 \mathrm{a}$ & $22,1 \mathrm{a}$ & $6,2 \mathrm{~b}$ & $2,2 \mathrm{~b}$ & $5,3 \mathrm{~b}$ \\
Trigo & $7,9 \mathrm{~b}$ & $44,4 \mathrm{~b}$ & $16,9 \mathrm{~b}$ & $11,0 \mathrm{a}$ & $6,2 \mathrm{a}$ & $13,5 \mathrm{a}$ \\
& & & & & & \\
CV (\%) & 17,8 & 3,9 & 7,8 & 15,7 & 29,0 & 13,8 \\
\hline
\end{tabular}

Médias seguidas por letras distintas, na coluna, diferem entre si pelo teste Tukey a $5 \%$ de probabilidade.

Meinerz et al. (2011), ao avaliarem silagens de cereais de inverno de duplo-propósito no estádio de grão pastoso, obtiveram valores superiores, de $30,89 \%$ de grãos na silagem de trigo BRS Tarumã. Quando a participação desse componente é pequena, a qualidade da fração fibrosa do caule, das folhas, da espiga e das palhas, combinada com a participação de cada um desses componentes, é determinante para o valor nutritivo (Barrière et al., 1997).

Para o $\mathrm{pH}$ das silagens (Tab. 3), houve diferença entre as espécies, com valores mais elevados para o trigo e mais baixos para a aveia. Mesmo os valores mais elevados mantiveram-se entre 3,8 e 4,2 , intervalo considerado ideal para a fermentação (Kung Júnior e Stokes, 2003). É importante considerar também que o valor de $\mathrm{pH}$ adequado para promover a eficiente conservação da forragem ensilada depende do conteúdo de umidade da silagem, do poder tampão, das concentrações de carboidratos solúveis e das condições de anaerobiose do meio (Fisher e Burns, 1987). Tendo em vista essas interações, Tomich et al. (2003) consideram que teores de MS abaixo de $20 \%$ apenas qualificam o processo de fermentação como adequado quando associados a valores de $\mathrm{pH}$ abaixo de 4,0. Nesse sentido, as associações entre MS e pH observadas neste trabalho não prejudicaram $o$ processo fermentativo.

Tabela 3. Parâmetros fermentativos da silagem da biomassa remanescente de pastagens de estação fria

\begin{tabular}{lccc}
\hline Espécie & $\mathrm{pH}$ & $\begin{array}{c}\text { Poder tampão } \\
\text { (eq.mg HCl/100g de MS) }\end{array}$ & $\mathrm{N}-\mathrm{NH}_{3}{ }^{*}$ \\
\hline Aveia & $3,78 \mathrm{c}$ & $14,52 \mathrm{~b}$ & $11,79 \mathrm{~b}$ \\
Azevém & $3,87 \mathrm{~b}$ & $19,07 \mathrm{a}$ & $11,96 \mathrm{~b}$ \\
Trigo & $4,09 \mathrm{a}$ & $19,46 \mathrm{a}$ & $14,05 \mathrm{a}$ \\
& & & 5,4 \\
\hline
\end{tabular}

Médias seguidas por letras distintas, na coluna, diferem entre si pelo teste Tukey a $5 \%$ de probabilidade.

* Em relação ao nitrogênio total.

O poder tampão das silagens (Tab. 3) foi diferente entre as espécies, com valor inferior para a aveia, o que permitiu queda rápida do $\mathrm{pH}$, mesmo com níveis mais baixos de MS. Os valores observados foram inferiores aos 25 eq.mg $\mathrm{HCl} / 100 \mathrm{~g}$ de MS sugeridos por McDonald et al. (1991) como valor esperado para capins. Valores inferiores aos encontrados no presente trabalho foram relatados por Bergen et al. (1991), que obtiveram poder tampão de 25,1 e 22,$3 ; 28,5$ e 20,$8 ; 17,5$ e 16 ,6eq.mg HCl/100g de MS para silagens de aveia, cevada e trigo, nos estádios de grãos leitoso e farináceo, respectivamente.
Com relação ao teor de nitrogênio amoniacal $(\mathrm{N}-$ $\mathrm{NH}_{3}$ ) das silagens, foi obtido maior valor para o trigo, acima do valor máximo preconizado por Ferreira (2001), de $10 \%$ do $\mathrm{N}$ total, para silagens de boa qualidade. $\mathrm{O}$ aumento do $\mathrm{N}-\mathrm{NH}_{3}$ é resultado da extensa hidrólise de proteínas nas primeiras 24 horas de ensilagem mediada, principalmente por enzimas da planta, enquanto as degradações subsequentes de aminoácidos ocorrem pela ação de microrganismos (Heron et al., 1986). A amônia que é formada nesse processo dificulta a rápida queda do $\mathrm{pH}$ da massa ensilada, aumentando o tempo para estabilização da forragem. Berto e Mühlbach (1997) relataram 
valores semelhantes aos do presente trabalho, entre 8,4 e $11,8 \%$ de $\mathrm{N}-\mathrm{NH}_{3}$, em relação ao $\mathrm{N}$ total, em silagens de aveia com préemurchecimento e adição de inoculantes.

Para a porcentagem de PB (Tab. 4), não foram observadas diferenças entre as espécies testadas nem entre as formas de conservação. Os valores médios de $\mathrm{PB}$ da silagem e do feno ficaram próximos a $12 \%$, acima do limite mínimo de $7 \%$ considerado por Van Soest (1994) para uma adequada fermentação ruminal. Os valores observados neste trabalho são superiores aos relatados por Floss et al. (2003), que, ao trabalharem com cultivares de aveia branca em diferentes estádios de maturação, obtiveram teores entre 8,4 e $5,7 \%$ de $\mathrm{PB}$.

Tabela 4. Percentuais de proteína bruta, nitrogênio insolúvel em detergente ácido (NIDA) e nitrogênio insolúvel em detergente neutro (NIDN) da silagem e do feno da biomassa remanescente de pastagens de estação fria

\begin{tabular}{|c|c|c|c|c|c|c|c|c|c|}
\hline \multirow{2}{*}{ Espécie } & \multicolumn{2}{|c|}{ Proteína bruta } & \multirow{2}{*}{$\begin{array}{l}\text { CV } \\
(\%)\end{array}$} & \multicolumn{2}{|c|}{ NIDA* } & \multirow{2}{*}{$\begin{array}{l}\text { CV } \\
(\%)\end{array}$} & \multicolumn{2}{|c|}{ NIDN* } & \multirow{2}{*}{$\begin{array}{l}\text { CV } \\
(\%)\end{array}$} \\
\hline & Silagem & Feno & & Silagem & Feno & & Silagem & Feno & \\
\hline Aveia & $12,32 \mathrm{aA}$ & $12,24 \mathrm{aA}$ & 6,2 & $11,18 \mathrm{aB}$ & $28,16 \mathrm{aA}$ & 19,8 & $24,34 \mathrm{aB}$ & $30,31 \mathrm{bA}$ & 5,3 \\
\hline Azevém & $11,34 \mathrm{aA}$ & $10,15 \mathrm{aA}$ & 7,6 & $13,03 \mathrm{aB}$ & $18,64 \mathrm{bA}$ & 7,4 & $28,60 \mathrm{aB}$ & $51,46 \mathrm{aA}$ & 4,5 \\
\hline Trigo & $11,67 \mathrm{aA}$ & $11,88 \mathrm{aA}$ & 4,0 & $14,53 \mathrm{aA}$ & $14,61 \mathrm{bA}$ & 14,7 & $22,46 \mathrm{aB}$ & $47,74 \mathrm{aA}$ & 5,5 \\
\hline CV $(\%)$ & 4,9 & 6,9 & & 10,0 & 19,0 & & 18,8 & 5,2 & \\
\hline
\end{tabular}

Médias seguidas por letras minúsculas, nas colunas, diferem entre si pelo teste Tukey, e por letras maiúsculas, nas linhas, pelo teste $\mathrm{F}$, a 5\% de significância.

* Em relação ao nitrogênio total.

Considerando os valores de NIDA e NIDN (Tab. 4) das silagens, não foram observadas diferenças entre as espécies. No entanto, verificou-se maior teor de NIDA no feno de aveia em relação ao azevém e ao trigo. Possivelmente, esse resultado se deve ao teor de MS mais baixo no momento da confecção, que resultou em intensa atividade microbiana e elevação da temperatura. Geralmente, os teores mais elevados de NIDA, que não é aproveitada pelos animais, estão também associados à formação de compostos de Maillard em decorrência da elevação da temperatura da forragem (Van Soest, 1994).

De forma geral, os teores de NIDA e NIDN foram maiores para $o$ feno em relação às silagens, o que pode ser explicado pelo fato de que o feno fica mais exposto a alterações devido à umidade relativa do ar, durante e após a desidratação, acarretando em períodos de aquecimento. Berto e Mühlbach (1997) também observaram aumento nos teores de NIDA quando a forragem foi submetida a períodos de desidratação. Os autores relataram valores mais baixos do que os do presente trabalho, de 7,1 e $8,1 \%$ de NIDA; e de 9,3 e $11,7 \%$ de NIDN, em relação ao $\mathrm{N}$ total, em silagens de aveia com e sem emurchecimento, respectivamente.
O teor de FDNcp das silagens foi maior para a aveia e o azevém, enquanto no feno o maior valor foi obtido para o azevém. Comparando-se as duas formas de conservação, teores mais baixos de FDNcp foram observados para as silagens de azevém e trigo, enquanto o menor valor foi observado para o feno de aveia. Comportamento semelhante foi observado para a FDAcp, com a aveia tendo apresentado menores teores no feno em relação à silagem, o que pode ser explicado pela maior indisponibilidade da proteína associada à parede celular, quantificada pelo NIDA e descontada da FDAc, decorrente do aquecimento sofrido pelo feno.

Os menores valores de FDNcp e de FDAcp das silagens foram obtidos para o trigo, indicando que a maior participação de grãos (Tab. 2), embora pouco expressiva, confere maior qualidade nutricional às silagens (Barrière et al., 1997). Fontaneli et al. (2009) relataram teores entre 49,9 e $55,2 \%$ de FDN e 22,7 e $29,9 \%$ de FDA em silagens de genótipos de cereais de inverno, inferiores aos observados no presente trabalho. Coan et al. (2001), ao avaliarem silagens de aveia amarela do genótipo São Carlos e aveia preta comum, obtiveram valores médios de 60,5 e $37,25 \%$ para essas variáveis, respectivamente, semelhantes aos observados nesta avaliação. 
Tabela 5. Percentuais de fibra insolúvel em detergente ácido (FDAcp) e neutro (FDNcp) corrigida para cinzas e proteína e carboidratos não fibrosos (CNF) da silagem e do feno da biomassa remanescente de pastagens de estação fria

\begin{tabular}{|c|c|c|c|c|c|c|c|c|c|}
\hline \multirow{2}{*}{ Espécie } & \multicolumn{2}{|c|}{ FDAcp } & \multirow{2}{*}{$\begin{array}{l}\text { CV } \\
(\%)\end{array}$} & \multicolumn{2}{|c|}{ FDNcp } & \multirow{2}{*}{$\begin{array}{l}\text { CV } \\
(\%)\end{array}$} & \multicolumn{2}{|c|}{ CNF } & \multirow{2}{*}{$\begin{array}{l}\text { CV } \\
(\%)\end{array}$} \\
\hline & Silagem & Feno & & Silagem & Feno & & Silagem & Feno & \\
\hline Aveia & $38,18 \mathrm{aA}$ & $36,02 \mathrm{cB}$ & 2,4 & $59,87 \mathrm{aA}$ & $50,16 \mathrm{cB}$ & 3,2 & $16,57 \mathrm{bA}$ & $15,84 \mathrm{aA}$ & 4,8 \\
\hline Azevém & $38,89 \mathrm{aB}$ & $45,70 \mathrm{Aa}$ & 1,9 & $61,15 \mathrm{aB}$ & $75,15 \mathrm{aA}$ & 1,3 & $17,27 \mathrm{bA}$ & $4,99 \mathrm{bB}$ & 9,5 \\
\hline Trigo & $35,14 \mathrm{bB}$ & $39,60 \mathrm{bA}$ & 2,2 & $56,04 \mathrm{bB}$ & $66,03 \mathrm{bA}$ & 1,2 & $21,76 \mathrm{aA}$ & $13,15 \mathrm{aB}$ & 5,3 \\
\hline CV (\%) & 1,9 & 2,4 & & 2,1 & 1,8 & & 3,8 & 9,7 & \\
\hline
\end{tabular}

Médias seguidas por letras minúsculas, nas colunas, diferem entre si pelo teste de Tukey, e por letras maiúsculas, nas linhas, pelo teste F, a 5\% de significância.

Para os teores de CNF (Tab. 5), os maiores valores da silagem foram observados para o trigo, enquanto para o feno os maiores valores foram obtidos para aveia e trigo. Esse resultado pode ser explicado pela menor participação de material morto e maior participação de grãos (Tab. 2), no caso do trigo. Resultados superiores foram relatados por Ferolla et al. (2008), que observaram valores de 21,17 e $22,82 \%$ de CNF para aveia preta e triticale sob corte, em diferentes épocas de semeadura. Para o feno, os maiores valores foram observados para a aveia $\mathrm{e}$ o trigo. Comparando-se as formas de conservação da forragem, houve menor valor de CNF no feno, e da aveia e do azevém para a silagem. Altos teores de CNF conferem boa qualidade às forragens conservadas, pois são compostos que favorecem o processo de fermentação, além de serem rápida e completamente digestíveis pelos ruminantes (Mertens, 1987).
Quanto aos teores de celulose e hemicelulose das silagens (Tab. 6), houve comportamento semelhante, com valores maiores para a aveia e o azevém. Para celulose e hemicelulose, os valores encontrados no presente trabalho foram semelhantes aos relatados por Coan et al. (2001), de 27,8 a $30,7 \%$ para celulose e entre 18,8 e $24 \%$ para hemicelulose, ao trabalharem com silagens de forrageiras de inverno submetidas ao préemurchecimento, com e sem aditivos. Para o feno, os maiores valores foram obtidos com o azevém e o trigo. Resultados inferiores foram relatados por Neres et al. (2011), que, ao avaliarem feno da mistura de tifton 85 e aveia preta com 100 dias de armazenamento, observaram 27,41 e $35,8 \%$ de celulose e hemicelulose, respectivamente. Os teores mais baixos de hemicelulose na silagem podem ser explicados pelo fato de que esse componente parece ser a principal fonte adicional de substrato para a fermentação, podendo ocorrer a utilização de até $40 \%$ dessa fração durante o processo fermentativo (Henderson, 1993).

Tabela 6. Percentuais de celulose, hemicelulose e lignina da silagem e do feno da biomassa remanescente de pastagens de estação fria

\begin{tabular}{|c|c|c|c|c|c|c|c|c|c|}
\hline \multirow{2}{*}{ Espécie } & \multicolumn{2}{|c|}{ Celulose } & \multirow{2}{*}{$\begin{array}{l}\text { CV } \\
(\%)\end{array}$} & \multicolumn{2}{|c|}{ Hemicelulose } & \multirow{2}{*}{$\begin{array}{l}\text { CV } \\
(\%)\end{array}$} & \multicolumn{2}{|c|}{ Lignina } & \multirow{2}{*}{$\begin{array}{l}\text { CV } \\
(\%)\end{array}$} \\
\hline & Silagem & Feno & & Silagem & Feno & & Silagem & Feno & \\
\hline Aveia & $35,02 \mathrm{aA}$ & $28,20 \mathrm{bB}$ & 5,2 & $23,31 \mathrm{aA}$ & $14,49 \mathrm{bB}$ & 9,3 & $4,54 \mathrm{aB}$ & $12,70 \mathrm{aA}$ & 5,3 \\
\hline Azevém & $34,25 \mathrm{aA}$ & $39,64 \mathrm{aA}$ & 4,7 & $24,02 \mathrm{aB}$ & $32,78 \mathrm{aA}$ & 3,6 & $6,12 \mathrm{aB}$ & $7,92 \mathrm{bA}$ & 9,4 \\
\hline Trigo & $30,76 \mathrm{bB}$ & $34,60 \mathrm{bA}$ & 4,3 & $21,83 \mathrm{bB}$ & $30,84 \mathrm{aA}$ & 0,4 & $6,07 \mathrm{aA}$ & $6,25 \mathrm{cA}$ & 8,6 \\
\hline CV $(\%)$ & 2,2 & 6,5 & & 3,0 & 5,8 & & 18,8 & 16,8 & \\
\hline
\end{tabular}

Médias seguidas por letras minúsculas, nas colunas, diferem entre si pelo teste de Tukey, e por letras maiúsculas, nas linhas, pelo teste F, a 5\% de significância.

Com relação ao teor de lignina das silagens (Tab. 6), não foi observada diferença entre as espécies. Para o feno, verificou-se maior teor para a aveia, decorrente das condições inadequadas de armazenamento, as quais, em razão do aquecimento excessivo, podem ter induzido a formação de lignina artificial pela reação de
Maillard (Van Soest, 1994). De forma geral, as silagens apresentaram menores teores de lignina em relação ao feno. A lignina está associada à FDAcp, sendo inversamente relacionada com a digestibilidade da forragem, uma vez que é a fração da fibra totalmente indigestível. Coan et al. (2001), ao trabalharem com silagem pré- 
emurchecida, observaram teores de lignina de $5,2 \%$ em genótipos de triticale e aveia, semelhantes aos observados para as silagens no presente trabalho.

Os teores de amido da silagem e do feno (Tab. 7) foram diferentes entre as espécies, com valores mais elevados para o trigo, provavelmente em razão da maior participação de grãos na massa de forragem (Tab. 2). Foram observados teores mais elevados de amido na silagem quando comparada ao feno, indicando que houve consumo de amido durante a sua conservação. McDonald et al. (1991) afirmam que o amido da forragem é indisponível para a maioria das bactérias, sobretudo as fermentadoras de lactato. No entanto, segundo Van Soest (1994), o amido pode ser degradado por outros microrganismos não produtores de lactato, principalmente fungos, proporcionalmente à sua atividade.

Tabela 7. Percentuais de amido, extrato etéreo e nutrientes digestíveis (NDT) totais da silagem e do feno da biomassa remanescente de pastagens de estação fria

\begin{tabular}{|c|c|c|c|c|c|c|c|c|c|}
\hline \multirow{2}{*}{ Espécie } & \multicolumn{2}{|c|}{ Amido } & \multirow{2}{*}{$\begin{array}{l}\text { CV } \\
(\%)\end{array}$} & \multicolumn{2}{|c|}{ Extrato etéreo } & \multirow{2}{*}{$\begin{array}{l}\text { CV } \\
(\%)\end{array}$} & \multicolumn{2}{|c|}{ NDT } & \multirow{2}{*}{$\begin{array}{l}\text { CV } \\
(\%)\end{array}$} \\
\hline & Silagem & Feno & & Silagem & Feno & & Silagem & Feno & \\
\hline Aveia & $0,33 \mathrm{cA}$ & $0,39 \mathrm{cA}$ & 22,8 & $2,75 \mathrm{aA}$ & $2,04 \mathrm{aA}$ & 19,3 & $62,12 \mathrm{aA}$ & $46,54 \mathrm{cB}$ & 1,1 \\
\hline Azevém & $4,91 \mathrm{bB}$ & $2,46 \mathrm{bA}$ & 15,6 & $1,86 \mathrm{bA}$ & $1,42 \mathrm{bA}$ & 16,6 & $58,14 \mathrm{aA}$ & $50,80 \mathrm{bB}$ & 1,4 \\
\hline Trigo & $6,16 \mathrm{aB}$ & $3,61 \mathrm{aA}$ & 8,6 & $1,80 \mathrm{bA}$ & $1,75 \mathrm{bA}$ & 11,2 & $59,43 \mathrm{aA}$ & $57,31 \mathrm{aB}$ & 1,3 \\
\hline CV $(\%)$ & 9,7 & 14,4 & & 4,4 & 13,9 & & 11,2 & 1,4 & \\
\hline
\end{tabular}

Médias seguidas por letras minúsculas, nas colunas, diferem entre si pelo teste de Tukey, e por letras maiúsculas, nas linhas, pelo teste F, a 5\% de significância.

Para o extrato etéreo (Tab. 7), os valores foram mais elevados para a aveia tanto para a silagem quanto para o feno. Comparando-se as formas de conservação, os teores de extrato etéreo foram similares.

Quanto à estimativa de NDT das silagens (Tab. 7), verificou-se similaridade entre as espécies. Os valores observados são semelhantes aos relatados por Cappelle et al. (2001), que, ao revisarem os teores de NDT de silagem de milho na literatura brasileira, verificaram valores mínimos de 55,47\% e máximos de 63,87\%. Para o feno, o maior valor de NDT foi observado para o trigo. Comparando-se os métodos de conservação, a silagem apresentou valores mais elevados de NDT em relação ao feno em decorrência dos maiores teores de CNF (Tab. 5), e menor participação de compostos indigestíveis, como o NIDA (Tab. 4) e a lignina (Tab. 6).

\section{CONCLUSÕES}

O valor nutritivo das silagens é similar entre as espécies avaliadas e caracteriza forragem de boa qualidade. Considerando as formas de conservação, a ensilagem apresentou menores perdas de componentes solúveis e proporcionou uma forragem com valor nutritivo mais elevado, sendo a forma mais indicada para conservar a biomassa remanescente de pastagens de estação fria. A biomassa remanescente de pastagens de forrageiras de estação fria apresenta condições satisfatórias para a conservação na forma de feno e de silagem, podendo ser utilizada como alternativa para produção de forragens conservadas de baixo custo.

\section{REFERÊNCIAS}

BARRIÈRE, Y.; ARGILLIERA, O.; MICHALETDOREAU, B. et al. Relevant traits, genetic variation and breeding strategies in early silage maize. Agronomie, v.17, p.395-411, 1997.

BERGEN, W.G.; BYREM, T.M.; GRANT, A.L. Ensiling characteristics of whole-crop small grains harvested at milk and dough stages. J. Anim. Ssci., v.69, p.1766-1791, 1991.

BERTO, J.L.; MUHLBACH, P.R.F. Silagem de aveia preta no estádio vegetativo, submetida à ação de inoculantes e ao efeito do emurchecimento. Rev. Bras. Zootec., v.26, p.651-658, 1997.

CAPPELLE, E.R; VALADARES FILHO, S.B.; SILVA, J.F.C.; CECON, P.R. Estimativas do valor energético a partir de características químicas e bromatológicas dos alimentos. Rev. Bras. Zootec., v.30, p.1837-1856, 2001.

COAN, R.; FREITAS, M.D.; REIS, R.A.; RODRIGUES, L.R.A. Composição bromatológica das silagens de forrageiras de inverno submetidas ou não ao emurchecimento e ao uso de aditivos. Ars Vet, v.17, p.58-63, 2001.

EDWARDS, R.A., McDONALD, P. Fermentation of silage: a review. Iowa: West Des Moines, 1978. 115p. 
EVANGELISTA, A.R.; LIMA, J.A. Silagens do cultivo ao silo. Lavras: UFLA, 2000. 196 p.

FERREIRA, J.J. Estágio de maturação ideal para ensilagem do milho e do sorgo. In: PEREIRA FILHO, I.A.; RODRIGUES, J.A.S.; CRUZ, J.C.; FERRE, J.J. (Eds). Produção e utilização de silagem de milho $e$ sorgo. Sete Lagoas: Embrapa Milho e Sorgo, 2001. p. 405-428.

FERROLA, F. S.; VÁSQUEZ, H.M.; SILVA, J.F.C. et al. Composição bromatológica e fracionamento de carboidratos e proteínas de aveia-preta e triticale sob corte e pastejo. Rev. Bras. Zootec., v. 37, p.197-204, 2008.

FISHER, D.S.; BURNS, J.C. Quality analysis of summer-annual forages. II. Effects of forage carbohydrate constituents on silage fermentation. Agron. J., v.79, p.242-248, 1987.

FLOSS, E.L.; BOIN, C.; PALAHANO, A.L. et al. Efeito do estádio de maturação sobre o rendimento e valor nutritivo da aveia branca no momento da ensilagem. Bol. Ind. Anim., v.60, p.117-126, 2003.

FONTANELI, R.S.; FONTANELI, R.S.; SANTOS, H.P. et al. Rendimento e valor nutritivo de cereais de inverno de duplo-propósito: forragem verde e silagem ou grãos. Rev. Bras. Zootec., v.38, p.2116-2120, 2009.

HENDERSON, N. Silage additives. Anim. Feed Sci. Technol., v.45, p.35-56, 1993

HERON, S.J.; EDWARDS, R.A.; PHILLIPS, P. The effect of $\mathrm{pH}$ on the activity of ryegrass (Lolium multiflorum) proteases. J. Sci. Food Agric., v.46, p.267-277, 1989.

KUNG JUNIOR, L.; STOKES, M. R. Silage additives. In: BUXTON, D.R.; MUCK, R.E.; HARRISON, J.H. (Eds.) Silage science and technology. Madison: American Society of Agronomy; Crop Science Society of America; Soil Science Society of America, 2003. p. 251-304.

MANUAL de adubação e calagem para os estados do Rio Grande do Sul e de Santa Catarina. 10.ed. Porto Alegre: SBCS-NRS, 2004. 400 p.

McDONALD, P.; HENDERSON, N.; HERON, S. The biochemistry of silage. 2.ed. Marlow: Chalcombe Publications, $1991.340 \mathrm{p}$.
MEINERZ, G.R.; OLIVO, C.J.; VIEGAS, J. et al. Silagem de cereais de inverno submetidos ao manejo de duplo-propósito. Rev. Bras. Zootec., v.40, p.20972104, 2011.

MERTENS, D.R. Predicting intake and digestibility using mathematical models of ruminal function. $J$. Anim. Sci., v.64, p.1548-1558, 1987.

MONKS, P.L.; FERREIRA, O.G.L.; GOULART, E.Q.; TERRES, A.L.S. Potencial forrageiro do arroz irrigado (Oryza Sativa L.) após a colheita dos grãos. Rev. Bras. Agrocienc., v.8, p.67-70, 2002

NERES, M A.; CASTAGNARA, D D.; MESQUITA, E.E. et al. Production of tifton 85 hay overseeded with white oats or ryegrass. Rev. Bras. Zootec., v.40, p.1638-1644, 2011.

OFFICIAL methods of analysis. 16.ed. Arlington: AOAC International, 1995.

PAZ, L.G.; MATOS, M.M.V.L.; AGUIAR, E.M.; LIMA, G.F.C. Fenação: aspectos técnicos da produção. Cienc. Vet. Trop., v.3, p.01-16, 2000.

PINTO, A.P.; MIZUBUTI, I.Y.; RIBEIRO, E.L.A. et al. Avaliação da silagem de bagaço de laranja e silagem de milho em diferentes períodos de armazenamento. Acta Sci. Anim. Sci., v.29, p.371-377, 2007.

PLAYNE, M.J.; McDONALD, P. The buffering constituints of herbage and of silage. J. Sci. Food Agric., v.17, p.264-268, 1966.

SILVA, D.J.; QUEIROZ, A.C. Análise de alimentos: métodos químicos e biológicos. 3.ed. Viçosa: UFV, 2002. $235 \mathrm{p}$.

TOMICH, T.; PEREIRA, L.G.R.; GONÇALVES, L.G. et al. Características químicas para avaliação do processo fermentativo de silagens: uma proposta para qualificação da fermentação. Corumbá: Embrapa Pantanal, 2003. 20 p. (Documentos, 57).

VAN SOEST, P. J. Nutritional ecology of the ruminant. Ithaca: Cornell University, 1994. $476 \mathrm{p}$.

WEISS, W.P.; CONRAD, H.R.; ST.PIERRE, N.R.A theoretically-based model for predicting total digestible nutrient values of forages and concentrates. Anim. Feed Sci. Technol., v.39, p.95-110, 1992. 